\title{
SENTIDOS DO SINDICALISMO NA VEJA DURANTE A DITADURA MILITAR
}

\author{
SENSES OF TRADE UNIONISM IN THE VEJA DURING THE MILITARY DICTATORSHIP
}

Recebido em 02.10.2018. Aprovado em 24.10.2018

Avaliado pelo sistema double blind review

DOI: http://dx.doi.org/10.12712/rpca.v12i4.22926

\author{
Guilherme Gustavo Holz Peroni \\ gustavoperoni@hotmail.com \\ Universidade Federal do Espírito Santo (UFES), Vitória/ES, BRASIL \\ ORCID: https://orcid.org/0000-0003-0670-7501
}

\section{Priscilla de Oliveira Martins-Silva}

priscillamartinssilva@gmail.com

Universidade Federal do Espírito Santo (UFES), Vitória/ES, BRASIL

ORCID: https://orcid.org/0000-0002-2922-6607

\section{Annor da Silva Junior \\ annorsj@gmail.com \\ Universidade Federal do Espírito Santo (UFES), Vitória/ES, BRASIL \\ ORCID: https://orcid.org/0000-0003-4124-5277}

\section{Resumo}

Objetivou-se neste artigo analisar os sentidos do sindicalismo disseminados pela Veja durante a ditadura militar (1968-1985) ocorrida no Brasil. Ancorou-se teoricamente a pesquisa na teoria das representações sociais. Metodologicamente, realizou-se uma pesquisa documental no acervo digital da Veja num total de 54 edições em que 134 artigos foram selecionados para a análise. Foram construídas 10 categorias de análise. A análise dos dados indicou que a repressão do governo ditatorial aos movimentos sociais, os fatos econômicos e o movimento Diretas Já são aspectos históricos centrais para a compreensão do sindicalismo. Concluiu-se que o novo sindicalismo surgiu com uma postura radical e esquerdista e foi fortemente combatido e reprimido pelo governo ditatorial; no entanto, também foi inserido positivamente no pensamento social como uma entidade importante para a reabertura política e para o desenvolvimento da democracia.

Palavras-chave: Sindicalismo. Mídias; Representações Sociais. Ditadura Militar.

\section{Abstract}

The objective of this article was to analyze the meanings of trade unionism disseminated by Veja during the military dictatorship (1968-1985) in Brazil. The research has been theoretically anchored on the theory of social representations. Methodologically, a documentary research was held in the digital collection of Veja in a total of 54 editions in which 134 articles were selected for the analysis. Ten categories of analysis were constructed. The analysis of the data indicated that the repression of the dictatorial government to social movements, economic facts and the social movement "Diretas já" are central historical aspects for the understanding of trade unionism. In conclusion, the new syndicalism emerged with a radical and left wing stance and was strongly opposed and repressed by the dictatorial government; however, it was also inserted positively in the social thought as an important entity for the political reopening and for the development of democracy.

Keywords: Trade unionism. Media. Social Representations. Military dictatorship. 


\section{Introdução}

O sindicato dos trabalhadores é uma instituição munida de força para intermediar as relações trabalhistas com o patrão (classe empresária) que o trabalhador isoladamente não possuiria (Castro, 2007). Daí a importância dos sindicatos na defesa dos direitos e interesses dos trabalhadores. $O$ sindicato pode ser definido como uma "associação profissional de pessoas da mesma atividade, cujos interesses visa defender" (Castro, 2007, p. 99). Os sindicatos surgiram na França e na Inglaterra no século XIX e nos Estados Unidos no século XX, em um momento em que as condições de trabalho eram excessivamente degradantes.

O movimento sindical brasileiro sempre esteve presente nas relações políticas. $O$ golpe militar de 1964, por exemplo, "foi apresentado pelos próprios golpistas como uma medida preventiva contra a implantação de uma suposta 'República Sindicalista"' (BoitoJr., 2005,p. 273). Em contrapartida, os sindicatos sempre foram disciplinados por estatutos legais, com exceção de alguns curtos períodos históricos, o que sempre ocasionou a supervisão e até mesmo o controle do Estado sobre os sindicatos (Boito Jr., 2005). Nesse contexto, acentua-se a importância e a influência do sindicalismo na política, na sociedade, na economia e nas relações de trabalho, assim como a influência destes no sindicalismo. Isso porque, como afirma Singer (2014), as ações humanas na política, na economia e na sociedade estão condicionadas de forma recíproca.

Do ponto de vista acadêmico os sindicatos e o sindicalismo têm sido objeto de interesse de estudiosos e pesquisadores que abordam a temática por meio de diferentes perspectivas. Por exemplo, Cotanda (2008) investigou a relação entre os sindicatos e o processo de inovação tecnológica e organizacional. Rosa (2004) investigou as faces do sindicalismo rural brasileiro no contexto da Zona da Mata de Pernambuco. Já Boito Jr. (2005) estudou a presença do sindicalismo na história política do Brasil. Antunes (2003; 1996) por sua vez, aborda os temas numa perspectiva mais crítica ao discutir as transformações no mundo do trabalho e os desafios e impasses do sindicalismo brasileiro. A pluralidade de perspectivas que essa temática possui indica a relevância do tema que transcende gerações.

A comunicação de massa, outro tema central desta pesquisa, tem sido objeto de estudos da sociologia e outras ciências sociais aplicadas. Os termos "meios de comunicação de massa" e "mídia" são utilizados de forma intercambiável para se referir a transmissão de informações entre pessoas e/ou grupos por meio de tecnologias para o alcance de um grande contingente de pessoas (massa). Esses meios podem ser a imprensa escrita, o rádio, a televisão, a internet, e outras formas de comunicação. Esse tipo de comunicação caracteriza-se, entre outros fatores, por ser de mão única e desequilibrada, com a presença de poucos produtores (ou emissores) e muitos receptores (Brym, Roberts, Lie \& Rytina, 2012).

Thompson (2002) afirma que o processo de mediação da cultura moderna está relacionado com o sistema capitalista e vem interligando as sociedades de diferentes partes do mundo. Dessa forma, pessoas que nunca interagiram podem compartilhar determinadas memórias coletivas, formas simbólicas e experiências devido à influência dos meios de comunicação de massa (Thompson, 2002).

Alguns autores são críticos dos meios de comunicação de massa. Esses autores afirmam que as mídias buscam induzir o pensamento social e individual. Como afirma Guareschi (2003), o poder simbólico dos meios de comunicação de massa é legitimador, assim como é um fator que direciona o pensamento social. Para Herz (2003), as mídias não respeitam a pluralidade de opiniões e de interpretações sobre uma determinada informação. Assim, a mídia pode tornarse "particularmente perversa e insidiosa porque se vale de condições, recursos técnicos e linguagens cuja operação e existência sequer é percebida pelo público" (Herz, 2003, pp. 11-12), ou seja, as mídias podem utilizar maneiras veladas e insidiosas para imporem os seus conteúdos, valores, normas e ideologias. Nesse contexto, Schroder (2003) ressalta a possibilidade de se obter diferentes resultados no processo de divulgação de uma mesma informação de acordo com o formato e os contornos atribuídos à mensagem.

Os indivíduos podem, todavia, serem críticos às informações divulgadas pelos meios de comunicação de massa (Guareschi, 2003). Herz (2003, p. 12) afirma que "os conteúdos produzidos e distribuídos pela mídia são assimilados pelo público em um complexo processo de elaboração, que pode envolver mediações críticas em graus variados", ou seja, o pensamento social e individual não é refém dos veículos de comunicação de massa.

Para ancorar a discussão desses dois temas, buscouse o suporte teórico da Teoria das Representações 
Sociais (TRS), caracterizada como uma abordagem da Psicologia Social que procura compreender as relações sociais cotidianas da vida humana em um nível mais propriamente social ou coletivo. Colocado de outra forma, a TRS se ocupa da compreensão da construção do pensamento e do conhecimento do senso comum na vida cotidiana, em especial na sua gênese e no seu uso nas interações sociais que se desenvolvem nos contextos contemporâneos (Sá, 1998; Almeida, 2009). Jodelet (2005) complementa que a TRS tem como questão compreender as normas, crenças, valores, sentidos, pensamentos, comportamentos e ideologias que atravessam o pensamento social e individual. Com isso, acentua-se que nesta pesquisa adotouse a TRS com o objetivo de estudar um dentre os vários elementos das representações sociais (RS) do sindicalismo, que são os sentidos do sindicalismo que circulam na sociedade brasileira.

Jodelet (2001) afirma que as RS "circulam nos discursos, são trazidas pelas palavras e veiculadas em mensagens midiáticas, cristalizadas em condutas e em organizações materiais e espaciais" (Jodelet, 2001, p. 17-18). Assim, ao abrir-se a possibilidade de observar as RS na mídia, pretende-se neste artigo, por meio do arcabouço teórico e conceitual da TRS, analisar um importante mecanismo de disseminação de RS, que são os meios de comunicação de massa, mais especificamente a imprensa escrita.

Diante desse panorama, em que o sindicalismo se faz importante nas relações trabalhistas e devido à possibilidade de realização de pesquisa que analise a disseminação de RS nos meios de comunicação de massa, este artigo evidencia a necessidade de se conhecer os sentidos do sindicalismo disseminados pela mídia impressa do Brasil, no caso em questão, pela Veja. Justifica-se a escolha da Veja como fonte de pesquisa, principalmente, devido a sua permanência e representatividade no contexto brasileiro (ANER, 2015; Peroni, 2015). Diante desse quadro emerge a seguinte problemática de pesquisa: quais são os sentidos do sindicalismo disseminados pela Veja durante a ditadura militar brasileira? ${ }^{1}$ Definiu-se como objetivo central identificar e analisar os sentidos do sindicalismo disseminados pela Veja durante o período da ditadura militar (1968-1985).

O presente artigo é relevante por potencializar um alargamento do olhar sobre a história do sindicalismo e suas significações e sentidos. Destarte, o sindicalismo também está intimamente ligado a evolução das relações trabalhistas no Brasil. São diversos os sentidos do sindicalismo que circulam numa organização e, da mesma forma, na sociedade brasileira. Ademais, a mídia, integrada e atenta ao contexto político, social e econômico, também constrói e põe a circular sentidos e valores, contribuindo para a construção de RS sobre o sindicalismo. Assim, este estudo é relevante por promover uma análise das informações relativas ao objeto representacional "sindicalismo", ao contribuir para a compreensão de como esses sentidos foram construídos historicamente pela Veja, responsável por construí-los e disponibilizá-los ao seu público consumidor.

Metodologicamente realizou-se uma pesquisa documental de natureza qualitativa para analisar textos jornalísticos que foram submetidos à análise de conteúdo (Bauer, Gaskell \& Allum, 2002; Franco, 2003; Sá-Silva, Almeida \& Guidani, 2009; Bardin, 2011).

Estruturou-se o texto em oito tópicos além da presente introdução. No segundo tópico abordam-se os aspectos relativos à TRS; no terceiro tópico, discorrese sobre a história do sindicalismo no Brasil durante o período da ditadura militar sob uma perspectiva crítica; no quarto tópico apresenta-se o método de pesquisa. Na sequência apresentam-se os resultados da pesquisa; no quinto e sexto tópicos são abordadas as considerações sobre a Veja e as categorias de análise; no sétimo tópico apresenta-se a análise e discussão dos dados, e; por fim, no último tópico, apresenta-se as considerações finais da pesquisa.

\section{A teoria das representações sociais (TRS)}

Serge Moscovici foi o primeiro estudioso a empregar o termo representação social, conceito este constante

\footnotetext{
${ }^{1}$ Apresenta-se neste artigo os resultados de uma parte de um projeto de pesquisa (Peroni, 2015) que investigou os sentidos sobre o sindicalismo no contexto brasileiro disseminados pela Veja em quatro períodos históricos: ditadura militar (1968 a 1985); $4^{\mathrm{a}}$ república ou redemocratização (1985 a 1990); globalização e neoliberalismo (1990 a 2002); e, era Lula e atualidade (2003 a 2013). Os dados aqui apresentados referem-se ao primeiro período, qual seja a ditadura militar.
} 
de sua obra originária nomeada La Psychanalyse: Son image et son publique (Moscovici, 2012). Em sua pesquisa inicial sobre as RS da psicanálise, Moscovici buscou entender como a psicanálise adquiriu uma nova significação para o senso comum, após sair do campo científico-especializado por intermédio dos meios de comunicação (Moscovici, 2012).

Nesse contexto, ao investigar os fenômenos sociais, descobrem-se diversos elementos que são saberes organizadores da realidade social, tais como: ideologias, atitudes, crenças, opiniões, normas, valores, imagens, cognição, sentidos, entre outros (Jodelet, 2001; 2005). Então, conceitua-se as RS como "uma forma de conhecimento, socialmente elaborada e partilhada, com um objetivo prático, e que contribui para a construção de uma realidade comum" (Jodelet, 2001, p. 21). Compreende-se que as RS são uma forma de conhecimento diferente do científico e que estudá-las torna-se importante para a apreensão das interações sociais e dos processos cognitivos (Jodelet, 2001).

Destaca-se que na TRS a relação entre sujeito e objeto é irredutível. Em outras palavras, as RS são sempre de um indivíduo sobre um objeto (Sá, 1998). As RS estão disseminadas nas instituições, nos processos comunicativos entre os sujeitos, nos meios de comunicação de massa, na cultura, nas instituições, nas práticas e nos pensamentos individuais. As RS são fenômenos, "por natureza, difusos, fugidios, multifacetados, em constante movimento e presentes em inúmeras instâncias da interação social" (Sá, 1998, p. 21). No estudo das RS, estas são transformadas em objetos manejáveis, ou seja, saem do campo dos universos consensuais de pensamento para o campo do universo reificado da ciência (Sá, 1998), sem a necessidade, como afirma Moscovici (2015), de se submeter o primeiro ao segundo.

Destarte, com o aumento do desenvolvimento científico e com a sua maior publicidade, os mundos reificados, por sua vez, tornam-se cada vez mais acessíveis e imediatos (Moscovici, 2015). Devido à maior proliferação de teorias, acontecimentos e informações, os conhecimentos que antes eram considerados específicos do universo reificado são transferidos, remodelados e reapresentados para o mundo consensual (Moscovici, 2015).

Ademais, como afirma Moscovici (2015), a principal função das RS é tornar familiar aquilo que inicialmente não era familiar. Esta função é possível devido aos dois processos formadores das RS: a objetivação e a ancoragem (Moscovici, 2015). A ancoragem tem como objetivo "ancorar ideias estranhas, reduzilas a categorias e a imagens comuns, colocá-las em um contexto familiar" (Moscovici, 2015, p. 60-61). No processo de ancoragem, um objeto é ancorado "quando ele passa a fazer parte de um sistema de categorias já existentes, mediante alguns ajustes" (Trindade, Santos \& Almeida, 2014, p. 146). Dessa forma, a análise do processo de ancoragem permite a compreensão dos múltiplos sentidos atribuídos a um determinado objeto (Trindade, Santos \& Almeida, 2014) de acordo com o contexto histórico e social. Já a objetivação busca dar concretude a algo abstrato, isto é, procura compreender como um conceito ou fenômeno adquire materialidade (Moscovici, 2015). Em suma, esses dois mecanismos são responsáveis por transformar o não-familiar em familiar da seguinte maneira: em princípio, transferindo determinado objeto para a esfera particular do sujeito, de forma que o indivíduo possa interpretá-lo e compará-lo; e, em seguida, possibilitando que o indivíduo reproduza tal objeto como algo que possa ver, tocar e controlar.

O foco de atenção neste artigo volta-se para o processo de ancoragem, uma vez que a proposta central está relacionada à identificação dos sentidos de sindicalismo no contexto da ditadura militar brasileira. Com isso, a investigação dos sentidos de sindicalismo disseminados pela mídia, mais especificamente pela Veja, torna-se viável do ponto de vista teórico e metodológico.

\section{O sindicalismo no Brasil durante o período da ditadura militar}

Durante a ditadura militar, os dirigentes sindicais foram fortemente perseguidos, a organização de greves foi proibida, os direitos obtidos por meio da Consolidação das Leis do Trabalho (CLT) foram desmantelados e o governo interviu profundamente nos sindicatos (Queiroz, 2007).

Segundo Singer (2014), os primeiros anos do regime militar foram marcados principalmente pelas seguintes políticas: (1) o Fundo de Garantia do Tempo de Serviço (FGTS) tornou-se obrigatório, o que facilitou a demissão dos trabalhadores e reduziu o regime de estabilidade por antiguidade; (2) o favorecimento das grandes empresas, principalmente as internacionais, mediante a justificativa de que apenas as grandes empresas trariam avanços tecnológicos ao Brasil; e, 
(3) o crédito foi ampliado para acelerar a expansão econômica.

Com estas medidas e alguns outros fatores, por exemplo, o investimento em infraestrutura, o Brasil vivenciou um surto de crescimento, chamado de "milagre econômico", em que houve um crescimento extraordinário do produto interno bruto (PIB) e da produção industrial e a incomum queda da inflação (Singer, 2014). Contudo, o milagre econômico agravou algumas questões sociais, como a concentração de renda, além de tornar o país dependente do capital internacional (Marques \& Rêgo, 2010). O período do milagre econômico foi um momento de muita miséria e dificuldades para muitos trabalhadores (Antunes, 2003). Para Singer (2014), o auge do milagre ocorreu em 1973, quando o crescimento do PIB atingiu quase $14 \%$ e, a partir de então, iniciou o processo de aumento da inflação e declínio do crescimento econômico. De 1974 a 1977 o crescimento do PIB flutuou, enquanto a inflação registrou uma inclinação ao aumento (Singer, 2014). O fim do milagre econômico ocorreu principalmente devido os seguintes fatos: (1) "não houve investimentos para abrir em tempo os pontos de estrangulamentos físicos contra os quais se passou a chocar, desde 1972" (Singer, 2014, p. 198), ou seja, não houve investimento suficientemente em mão de obra qualificada e infraestrutura de transportes, energia e comunicações; (2) descontrole inflacionário; e, (3) crise do petróleo de 1973 (Singer, 2014).

Singer (2014) acredita que o vigor da economia de 1968 a 1974 isolou os grupos que se rebelaram contra o regime nesse período, ou seja, esses grupos não tiveram o devido apoio popular. Nesse contexto, em 1968 foram organizadas grandes greves, por exemplo, as greves de Contagem e de Osasco, que duraram poucos dias, devido à grande repressão das forças militares, o que significou uma derrota para o movimento sindical e operário (Antunes, 2003). A intervenção militar nos sindicatos e a proibição das greves foram algumas das atitudes tomadas pelo governo militar para interromper a espiral de preços e salários (e da inflação). Os aumentos salariais eram considerados como os principais responsáveis pela aceleração dos preços (Singer, 2014).

Em 1977, após anos de arrocho salarial e redução do índice de aumento salarial, os operários começaram a se mobilizar em busca de melhores condições salariais. Em maio de 1978, os trabalhadores iniciaram as greves, que teve o apoio de centenas de milhares de operários metalúrgicos de todo o estado de São
Paulo (Antunes, 2003). Ao saírem vitoriosos, os trabalhadores e os sindicatos iniciaram a luta contra o arrocho salarial instaurado desde o fracasso do movimento dos trabalhadores em 1968, assim como fizeram letra morta a legislação repressiva do período ditatorial, como a Lei Antigreve e a obrigação da estrutura sindical subordinada ao Estado (Antunes, 2003). Esse período foi significativo por sinalizar o ressurgimento do movimento sindical e proporcionar experiências de luta e organização dos trabalhadores. Foram as oposições dos operários do complexo industrial do $\mathrm{ABC}$ Paulista que serviram de referência para diversos movimentos grevistas pelo Brasil (Alves, 2000).

Em 1979, ocorreu a segunda crise do petróleo que, aliada a crise do endividamento externo, provocou o descontrole dos preços, a redução da produção e o desemprego em massa. A segunda crise do petróleo ocasionou uma profunda crise econômica no Brasil até 1983 (Singer, 2014). Nesse contexto, os metalúrgicos do ABC Paulista deflagraram greve geral em 1979. Foi reivindicada a volta das lideranças sindicais cassadas e foram realizadas diversas assembleias populares (Antunes, 2003). A greve de 1979 teve o apoio de setores da imprensa e de parcela do partido de oposição à ditadura militar, o Movimento Democrático Brasileiro (MDB), devido à insatisfação de parte da burguesia com o declínio do milagre econômico (Boito Jr., 2005). Nesse período, foi consolidada a liderança de Luiz Inácio da Silva, o Lula, com o apoio de todos os sindicatos do país que lutavam contra as arbitrariedades do governo militar (Antunes, 2003).

Para Boito Jr. (2005), as novas lideranças sindicais, principalmente do ABC Paulista, defendiam a livre-negociação entre empresários e categoria de trabalhadores, pois não reconheciam a importância do governo e da política como propiciadores de melhores condições trabalhistas e de vida aos trabalhadores. Antunes (2003) afirma que esse movimento que iniciou em 1978/1979 foi primordial para o rompimento com as políticas econômicas antipopulares instauradas a partir de 1964, assim como deu início ao chamado novo sindicalismo (Alves, 2000). Segundo Cardoso (2002), o novo sindicalismo buscou atingir os trabalhadores de chão de fábrica, ou seja, buscou-se "horizontalizar a representação sindical” (Cardoso, 2002, p. 26).

A partir de então a classe trabalhadora passou a duelar com os patrões e com o governo em busca de melhores salários (Alves, 2000). Ocorreram diversas 
greves por categorias, greves gerais e por empresas no decorrer dos anos de 1980, indicando "o espírito de luta e resistência operária e popular, de um Brasil que clamava por democracia política e social" (Alves, 2000, p. 112). No ano de 1980 foi oficializado o Partido dos Trabalhadores (PT).

Segundo Santana (2002), em 1983 foi realizada a primeira greve geral desde 1963 . Todos os grandes centros urbanos do país foram paralisados. As reivindicações eram basicamente de caráter político, ou seja, contra "o FMI [Fundo Monetário Internacional], pela reforma agrária, por uma assembleia nacional constituinte soberana, contra o arrocho salarial, contra a recessão" (Cardoso, 2002, p. 29). No mesmo ano foi criada a Central Única dos Trabalhadores (CUT), rompendo-se assim com a estrutura sindical oficial (Queiroz, 2007).

Em decorrência desse cenário político e social, estruturou-se o movimento Diretas Já, que teve como objetivo a retomada das eleições diretas ao cargo de presidente da República. Observou-se nesse período a intensa participação operária e popular (Alves, 2000). O movimento sindical também participou e influenciou na mobilização da população brasileira. Para Boito Jr. (2005), o surgimento do PT e da CUT configurou-se como a gênese de uma nova força social que elevou a crise do governo militar e que participou da campanha Diretas Já e da consequente superação da ditadura militar. Assim, novamente constata-se a participação e influência do movimento sindical no processo político e social brasileiro.

\section{Metodologia}

Esta pesquisa, de natureza qualitativa, tem como objetivo realizar uma análise de elementos textuais para a compreensão do fenômeno estudado (Bauer, Gaskell \& Allum, 2002), ou seja, do sindicalismo. A consulta a textos jornalísticos foi adotada como estratégia de coleta de dados (Sá-Silva, Almeida \& Guidani, 2009). Dessa forma, realizou-se uma pesquisa documental na revista semanal Veja. Foram selecionados e analisados apenas dados textuais, ou seja, notícias, reportagens, notas de opinião, notas informativas, entrevistas e comentários sobre o sindicalismo na classe operária.

Acentua-se que os documentos pesquisados são de conhecimento público e estão disponíveis gratuitamente no acervo digital da Veja. Por esse motivo, não foi necessário submeter esta pesquisa ao comitê de ética em pesquisa por se tratar de pesquisa com documentos disponíveis ao público.

Sabe-se que a ditadura militar foi instaurada em $1^{\circ}$ de abril de 1964, todavia, a primeira edição da revista Veja foi publicada em 11 de setembro de 1968. Dessa forma, o período histórico investigado inicia em 11 de setembro de 1968 e termina em 14 de março de 1985. Visto que o período histórico estudado é extenso, adotou-se a seleção de uma edição a cada quatro meses. Para maior sistematização, privilegiou-se a primeira edição do respectivo quadrimestre. Dessa forma, selecionou-se a primeira edição da revista Veja até a edição 852, de 2 de janeiro de 1985. Nas edições 243, 261, 330, 644 e 678 nenhuma matéria foi encontrada com os termos chaves. Nesses casos, avançou-se para a próxima edição. Também foi pertinente $\mathrm{o}$ estudo de quatro edições semanais extraordinárias em consonância com os fatos históricos relevantes, quais sejam as edições 507, 551, 590 e 777 . Foi investigado um total de 54 edições da revista.

Para a localização dos textos foram utilizadas as palavras chaves sindicalismo, sindical (is) e sindicato (s) no local de busca do acervo digital da Veja. A pesquisa foi realizada em cada edição. Todo o material foi impresso, inventariado, lido, codificado e analisado. As palavras chaves foram destacadas em todo o material impresso para orientação do pesquisador.

A análise de conteúdo foi utilizada como método de análise do material. Optou-se pela análise de conteúdo por ser uma técnica de tratamento de material textual e simbólico (Colbari, 2014). Ressalta-se que se buscou neste trabalho uma aproximação aos aspectos semânticos da linguagem e um distanciamento de uma compreensão que valoriza unicamente a palavra, ou seja, buscou-se descrever, analisar e interpretar os sentidos atribuídos às mensagens escritas (Franco, 2003).

Para isso, realizou-se inicialmente uma leitura flutuante dos documentos selecionados (Bardin, 2011). Durante a leitura flutuante emergiram as primeiras impressões sobre o fenômeno. Em seguida, procedeu-se a leitura dos artigos e a elaboração dos indicadores (Bardin, 2011). Para a sistematização do conteúdo dos sentidos do sindicalismo foram elaboradas categorias de análise a partir dos dados encontrados sob uma dimensão qualitativa e semântica (Bardin, 2011; Colbari, 2014). Assim, os indicadores foram agrupados em categorias (Bardin, 2011, Colbari, 2014), ou seja, reuniram-se os indicadores com sentidos, significados e temas em 
comum. As categorias de análise foram construídas $a$ posteriori e validadas por três juízes externos.

Após a construção das categorias de análise, passou-se para a realização de inferências (Franco, 2003; Bardin, 2011). Bardin (2011) afirma que a finalidade da análise de conteúdo é a inferência de conhecimentos relativos às condições de produção e mesmo de recepção, inferência essa que recorre a um conjunto de indicadores que podem ser quantitativos ou não (Bardin, 2011), ou seja, é o procedimento essencial para a adequada interpretação das categorias de análise construídas na fase de descrição.

A seguir serão apresentados os resultados da pesquisa em três tópicos. O primeiro sobre a Veja e o acervo pesquisado referente ao período investigado, o segundo sobre as categorias de análise, também relativo ao período investigado e o terceiro e último tópico a discussão dos resultados.

\section{A Veja}

A Veja foi selecionada como fonte de dados para a pesquisa pela representatividade e circulação no contexto brasileiro, bem como pela longevidade de suas publicações. A editora Abril fez uma extensa campanha para o lançamento da Veja, no entanto, a Veja solidificouse no mercado brasileiro somente em meados da década de 1970 (Brandão \& Silva, 2017). Em 1988, a Veja tornou-se a $5^{a}$ maior revista semanal de informação do mundo ao atingir a tiragem de 800 mil exemplares (Mira, 2001). Segundo os dados da Associação Nacional de Editores de Revista (ANER), a Veja ocupou a $1^{a}$ posição no ranking de revistas semanais em circulação no Brasil em 2014, com uma média de circulação de 1.167.928 exemplares por edição no período de janeiro a setembro de 2014, sendo seguida pelas revistas Época (390.709 exemplares por edição) e IstoÉ (322.518 exemplares por edição) (ANER, 2015). Além disso, a Veja está em circulação desde o ano de 1968 em que foi criada pelos jornalistas Roberto Civita e Mino Carta, com publicações ininterruptas até os dias de hoje (Menandro, Trindade \& Almeida, 2003; Grupo Abril, 2015), abrangendo, portanto, um longo período histórico.

Os primeiros anos da Veja foram marcados pela influência dos fatos publicados na imprensa internacional. Durante a ditadura militar, as agências internacionais de notícias interferiram na elaboração das notícias publicadas pela imprensa brasileira (Klanovicz, 2010). Vale ressaltar também que a Veja desenvolveu-se juntamente com o regime militar. Assim, diversas vezes a Veja esteve "às voltas com a censura, teve exemplares apreendidos e, como o restante da imprensa, esteve vários anos sob censura prévia" (Mira, 1997, p. 121). Em meados da década de 1970, a pressão do regime militar sobre a Veja aumentou, principalmente com relação ao jornalista Mino Carta, que por esse motivo foi demitido em 1975 (Mira, 1997).

Por fim, destaca-se que a Veja dita normas e condutas compatíveis com os seus valores, crenças e ideologia (Augusti, 2008). Por exemplo, Rautenberg (2012) sugere que a Veja teve vínculos com empresas da construção civil e com o regime militar. Assim, a pesquisa documental de Rautenberg (2012) revelou diversos posicionamentos da Veja de apoio ao governo ditatorial como, por exemplo, o apoio às grandes obras que estavam sendo realizadas e ao progresso que a ditadura militar estava promovendo ao Brasil, demonstrando, assim, que o relacionamento da Veja com a ditadura militar estava além da subordinação. Além disso, ainda segundo Rautenberg (2012), a Veja apoiou as construtoras das grandes obras do período da ditadura militar e, em diversas matérias, a Veja demonstrou admiração e reconhecimento a Delfim Netto, devido a satisfação do proprietário do Grupo Abril na época, Victor Civita, com as políticas econômicas desenvolvidas pelo Ministro. Diante desse contexto, a Veja viabiliza a circulação e a formação de RS (Moscovici, 2015) sobre diversos fenômenos sociais, inclusive sobre o sindicalismo, condicionandoos às suas normas, valores, crenças e ideologia que representa uma parte da realidade social da época.

\section{Os resultados}

Referente ao período da ditadura militar foi pesquisado no acervo digital da Veja um total de 54 edições, sendo selecionados 134 artigos para a análise. Após a utilização da técnica de análise de conteúdo foram identificadas 10 categorias. A Tabela 1 apresenta a frequência ${ }^{2}$ das categorias de análise.

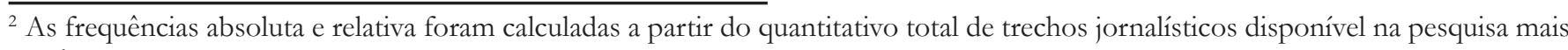
ampla.
} 
Tabela 1. Frequência das categorias de análise.

\begin{tabular}{|c|c|c|}
\hline Título da Categoria & Frequência absoluta & Frequência relativa \\
\hline Importância do sindicato para o país e para os trabalhadores & 7 & $9 \%$ \\
\hline Negociação sindical & 3 & $4 \%$ \\
\hline Vigor do sindicalismo e greves & 8 & $11 \%$ \\
\hline Liberdade sindical & 7 & $9 \%$ \\
\hline Corrupção, peleguismo e financiamento sindical & 5 & $7 \%$ \\
\hline Dificuldades enfrentadas pelos sindicatos & 4 & $5 \%$ \\
\hline $\begin{array}{c}\text { Sindicatos indicados como responsáveis pela perturbação da } \\
\text { ordem pública }\end{array}$ & 11 & $15 \%$ \\
\hline Intervenção e repressão & 19 & $25 \%$ \\
\hline O sindicalismo brasileiro relacionado a lideranças sindicais & 6 & $8 \%$ \\
\hline As transformações do mundo do trabalho & 5 & $7 \%$ \\
\hline
\end{tabular}

Fonte: Elaborada pelos autores.

Devido ao grande volume de dados obtidos, foram selecionados e apresentados a seguir apenas alguns trechos jornalísticos que representam e exemplificam as respectivas categorias. Esses trechos ilustram para o leitor a relação entre o conteúdo da mensagem disseminada e a sua classificação na categoria por meio da análise de conteúdo (Franco, 2003; Bardin, 2011). Os excertos foram referenciados com a identificação do ano de publicação, edição e a página de publicação na Veja e cada categoria foi referenciada com a letra C de categoria e um número de acordo com a ordem de identificação.

\section{Importância do sindicato para o país e para os trabalhadores (C.1)}

Em alguns trechos, os sindicatos ou questões sindicais foram incluídos num conjunto de organizações ou assuntos importantes para um país. Destarte, o apoio sindical foi considerado estratégico para o governo e os sindicatos foram considerados importantes para a defesa dos interesses de trabalhadores e, até mesmo, para a abertura política.

"Vamos fazer a cobertura de política, qualidade de vida na cidade, movimento sindical e cultural", acrescenta Silvio Júlio... (1977, 470, p. 91).

... Com a história, aprende-se que o movimento sindical, em si, é um fator de iluminação e progresso da sociedade... (1980, 609, p. 88).

\section{Negociação sindical (C.2)}

Nesta categoria, reuniram-se os trechos em que os dados transmitiram a imagem de sindicatos negociadores. Em alguns casos, os sindicatos foram responsáveis pelas negociações trabalhistas e por intermediações dos conflitos de interesses com o governo e com o patronato.

... Lula telefonou para Macedo dizendo que os sindicatos de São Bernardo e São Caetano aceitavam o acordo para submetê-lo às assembleias gerais. Macedo comunicou ao Planalto que iria fechar o negócio com os dois sindicatos... (1979, 551, p. 123). 


\section{Vigor do sindicalismo e greves (C.3)}

Inicialmente, durante o período em que as greves eram fortemente coibidas pelo regime militar, o movimento grevista não era o foco de discussão da Veja. Assim, constataram-se neste período apenas alguns relatos de sindicalistas que clamavam pela greve de forma legal ou ilegal.

\section{... a Federação promoven boicote aos refeitórios da Petrobrás e anunciava "greve legal on ilegal" pelo aumento... (1968, 1, p. 29).}

Com o processo de abertura política, mais fortemente no governo de João Figueiredo (15 de março de 1979), alastraram-se pelo país os movimentos grevistas. A partir de então, pode-se observar efetivamente notícias sobre os movimentos grevistas.

\section{... mesmo que quisessem agora encerrar a greve, os lideres sindicais reunidos no apartamento paulista de Murillo Macedo tinham pela frente assembleias altamente radicalizadas pelo clima dos dias anteriores - sobretudo Lula, que teria de falar para 80.000 operários... (1979, 551, p.121).}

Nesse contexto, o vigor do novo sindicalismo foi explicitado por meio da união dos trabalhadores e pelo sucesso conquistado pelos movimentos grevistas. Com o crescimento do novo sindicalismo, os sindicatos foram considerados poderosos e mobilizadores dos trabalhadores.

...é de se admitir que alguma preocupação com o crescimento do sindicalismo chamado "autêntico" - que busca sua total desvinculação do Ministério do Trabalho - exista realmente... (1979, 556, p. 26).

... Dirigentes de poderosos sindicatos paulistas e seus assessores... (1979, 574, p. 94).

\section{Liberdade sindical (C.4)}

A discussão sobre a liberdade sindical e a sua importância para os trabalhadores também foi observada nos dados. Tal discussão tornou-se relevante principalmente a partir do início da abertura política do país, em que começaram a surgir os movimentos sociais e políticos que questionavam a forte repressão adotada pelo regime militar.

\section{Tudo poderá ser bem diferente quando os desdobramentos da abertura gerarem uma efetiva liberdade sindical... (1979, 556, p. 22). \\ ... Diante do microfone, deverão se suceder 26 oradores defendendo o direito de greve, a garantia de emprego, a liberdade $e$ autonomia sindical... (1979, 556, p. 26).}

Nesse ínterim, alguns dados demonstraram uma entonação crítica ou discordante por parte da Veja ao examinar algumas ações e políticas adotas pelo governo perante o movimento sindical, como, por exemplo, assassinatos, controle da força de trabalho, política salarial, estrutura sindical, participação política dos trabalhadores, intervenções nos sindicatos, modelo econômico e greves.

\section{... Se houvesse condições de fazer uma verdadeira greve geral no Brasil, o país seria outro, os pacotes econômicos não baixariam mensalmente e a politica salarial, certamente, não seria a que boje vigora (1983, 777, p. 31).}

\section{Corrupção, peleguismo e financiamento sindical (C.5)}

Incluíram-se nesta categoria alguns excertos que trataram dos seguintes assuntos: (a) peleguismo, em que alguns sindicatos ou sindicalistas dialogaram com o governo sobre determinados assuntos sem consultar a base ou com interesses contrários à da base da categoria; (b) sindicatos que cederam às pressões do patronato; (c) sindicatos que realizaram conluios para a realização de greves; (d) minoria sindical que trabalhou para conquistar anseios pessoais; (e) sindicalistas que foram acusados de aceitarem regalias em troca de favores pessoais.

\footnotetext{
"Se as confederações cumprissem seu papel", diz Marcilio, "não seria preciso criar uma central". Mas o que se vê são as cúpulas atuando em nome dos trabalhadores sem beneficiá-los... (1978, 504, p. 84).
} 
... Talvez sua figura mais detestada seja a do pelego, esta espécie de alcaguete, como Deoclécio de Hollanda Cavalcanti, que tinha até Cadillacs, em 1946, como dirigente sindical (1980, 609, p. 87).

... E, diabolicamente sofisticado, sobra - Imposto Sindical, instrumento de corrupção, empecilho à verdadeira sindicalização (1980, 609, p. 88).

\section{Dificuldades enfrentadas pelo sindicalismo (C.6)}

Os dados demonstraram algumas dificuldades enfrentadas pelo sindicalismo, como: (a) a baixa quantidade ou a queda do número de sindicalizados; (b) desunião da classe de trabalhadores; (c) enfraquecimento dos sindicatos; e, (d) inabilidade e inexperiência de alguns líderes sindicais.

...vê na fraqueza dos sindicatos que
representam atores e na desunião da
classe, osprincipaisfatores que impediram
a regulamentação da profissão dos
artistas... (1974, 295, p. 78).
...os movimentos grevistas são
frequentemente conduridos por guias
inexperientes, entregues à emoção
e ao radicalismo das assembleias.
Reivindicações de atendimento impossivel
se multiplicam, e, muitas vezes, o controle
dos movimentos se esvai por difusos,
desorientados comandos gerais' (1979,
556, p. 22).

Sindicatos indicados como responsáveis pela perturbação da ordem pública (C.7)

Os sindicatos foram considerados entidades indagadoras e contra os objetivos do governo ditatorial. Assim, os sindicatos deveriam ser pacificados, mitigados e reprimidos. Há casos em que os sindicatos foram inseridos no conjunto de radicais, por exemplo, milícias, terroristas, agitadores sociais e financiadores da esquerda.

... Os incendiários, na hipótese levantada pelo ministro, seriam os exilados que retornam, os presos que são libertados e os politicos e dirigentes sindicais que estão à frente de campanhas de reivindicações sociais (1979, 574, p. 26).

Nesse contexto, alguns trechos demonstraram uma argumentação ou entonação de defesa ao regime militar e ao patronato e/ou de crítica ao sindicalismo, ao tratar de assuntos como: (a) prejuízos causados pelas greves; (b) pouca moderação das manifestações dos grupos sociais; (c) anseio demasiado dos trabalhadores por melhores condições salariais; (d) inviabilidade do projeto de criação do PT; e, (e) preocupação com as badernas e depredações durante as passeatas e movimentos grevistas.

... Os operários, é certo, podem continuar impondo duros prejuizos às empresas e tornando caótica a produção no $A B C$, com a continuação da greve... (1979, 551, p. 118).

Hoje, a disposição de ganhar mais dinheiro tem levado à greve, quase automaticamente, amplas categorias sociais (1979, 556, p. 22).

... Exceto algumas vidraças do edifício do INAMPS [Instituto Nacional de Assistência Médica da Previdência Social], quebradas em Porto Alegre depois de uma passeata, e algumas dezenas de ônibus depredadas em São Bernardo... (1983, 777, p. 29).

\section{Intervenção e repressão (C.8)}

Os dados também demonstraram a intenção do Estado de interferir nos sindicatos, ou seja, o desejo de judicializar e legalizar o sindicalismo durante o período ditatorial. Assim, foram relatados atos ou intenções do governo de interferir no meio sindical, como: (a) o não reconhecimento das centrais e federações sindicais, pelo fato de não existirem leis que tratavam de sua criação e normatização; (b) não reconhecimento dos atos dos sindicatos que desatenderam a lei; (c) legalização da greve; (d) intervenção nas contribuições sindicais para atender as despesas governamentais; (e) intervenção nas cúpulas dos sindicatos; e, (f) ilegalidade da sindicalização de servidores públicos.

... O delegado do Trabalho em Pernambuco dir que intervirá no Sindicato "se romper 
as negociações antes do prazo legal'... (1968, 1, p. 29).

... Na madrugada da sexta-feira, enfim, foi decretada intervenção federal nos poderosos sindicatos metalúrgicos de São Bernardo do Campo, Santo André e São Caetano do Sul, e a polícia cercou as sedes das entidades (1979, 551, p. 22).

Outros excertos evidenciaram a intenção do governo de transferir ou impor algumas tarefas aos sindicatos, como: (a) Previdência Social; (b) rescisão de contratos de trabalho; (c) assistencialismo; (d) pagamento do $13^{\circ}$ salário e férias; e, (e) prestação de assistência jurídica aos trabalhadores, sindicalizados ou não.

...o presidente anunciou três medidas principais... 2) a entrega de parte das atribuiçôes assistenciais da Previdência Social aos sindicatos... (1970, 87. p. 20).

... a dispensa da homologação das juntas de conciliação para as rescisões de contratos de trabalho, tarefa que passa a ser executada pelos sindicatos... (1970, 87, p. 20).

Os dados também apresentaram diversos atos ou intenções de repressão contra sindicatos e sindicalistas do Brasil e de outros países. Tais atos ou intenções de repressão contavam com a utilização das forças armadas, geralmente amparadas pela Lei de Segurança Nacional ou similar, como os agentes da Polícia Militar e da Delegacia de Ordem Política e Social (DEOPS), que se valeram de alguns instrumentos como bombas de gás lacrimogênio, prisão, sequestro e tortura.

\section{... Os policiais iniciaram o cerco ao sindicato distribuindo bombas de gás lacrimogêneo pelas ruas que circundam a entidade... (1979, 551, p. 124). \\ ...afastar e punir com a Lei de Segurança Nacional todo dirigente sindical que for acusado de incitar greves ilegais... (1979, 574, p. 95).}

Também foram encontrados alguns relatos de sindicalistas mortos (ou assassinados) por diversos motivos, assim como foram expostos casos de patrões ameaçando sindicalistas de morte. Em alguns casos, a Veja apresentou algumas suposições para as mortes, por exemplo, ligações dos sindicalistas com atividades subversivas e/ou com o movimento de esquerda e resistência aos regimes ditatoriais.

... O presidente do Sindicato [...] conta que o arrendatário do Engenho do Monte..., ao mostrar-lhe um revólver numa discussão na Delegacia do Trabalho, ameaçou "apagá-lo do pasto"... (1968, 1, p.29).

... No relatório do inquérito que investigou a misteriosa morte de Olavo Hansen (ex-lider sindical, acusado de atividades subversivas)... (1970, 104, p. 32).

\section{0 sindicalismo brasileiro relacionado a lideranças sindicais (C.9)}

Constatou-se a influência do líder sindical Luís Inácio da Silva, o Lula, no sindicalismo brasileiro. Lula foi considerado como o principal articulador dos movimentos grevistas e da renovação do sindicalismo brasileiro. A Veja preocupou-se em publicar detalhes da vida pessoal, profissional e sindical do Lula. Não só o sindicalismo brasileiro, mas também o PT e a CUT mesclaram-se com a imagem de Lula. Diversos nomes de sindicalistas influentes da época foram citados, como Joaquim dos Santos Andrade (Joaquinzão), Antônio Rogério Magri e Argeu Egídio dos Santos. Entretanto, nenhum deles foi tão mencionado e relacionado ao sindicalismo brasileiro quanto Lula.

No inicio da tarde de sexta-feira, já recolbido à casa de parentes de sua mulher - um modesto sobrado em São Bernardo do Campo - Lula tomou banho, vestiu um calção e, de cabelos molhados e pés descalcos, olhos vermelhos das noites sem dormir, sentou-se à frente da televisão para assistir o noticiário que falava da intervenção do sindicato dos metalúrgicos de São Bernardo do Campo, que ele presidiu nos últimos quatro anos... (1979, 551, p. 120).

Em sua especialidade, lidar com os metalúrgicos do ABC Paulista, Lula foi de longe a maior figura do sindicalismo nos anos 70... mesmo destituído...liderou 160.000 metalúrgicos numa greve de 15 dias...tomon a iniciativa das negociações com o governo e descobriu os telefones de vários ministros de Figueiredo (1979, 590, p. 48). 


\section{As transformações do mundo do trabalho (C.10)}

Os sindicatos foram acusados de terem obtido conquistas trabalhistas consideradas exageradas. Sob outros aspectos, as transformações do mundo do trabalho foram destacadas como responsáveis pelas relações estremecidas entre os sindicatos, governo e patronato.

...presidente do sindicato das Pequenas
Estruturas, Alvaro Bolaventa: "Agora
que a lei da oferta e daprocura pende para
o lado dos operários, não sei onde vamos
parar. Somos obrigados a dar alojamento,
chuveiro quente, cantina e até aguentar
desaforo. Alguns chegam a querer refeição
de graça" (1973, 262, p. 84).

\section{Discussão}

O suporte teórico da TRS permitiu a identificação de 10 categorias de análise que desvelam os sentidos do sindicalismo disseminados pela Veja no período da ditadura militar (1968-1985). As categorias de análise representam a transformação das RS do sindicalismo em objetos manejáveis (Sá, 1998). Isso porque, conforme afirma Jodelet (2001), as RS circulam em discursos presentes em palavras veiculadas nos meios de comunicação. Com isso, a construção das categorias de análise reflete os sentidos disseminados pela Veja (Sá, 1998), observados o contexto histórico, político, econômico e social da época (Trindade, Santos \& Almeida, 2014) e as normas, valores, opiniões, crenças e ideologia da Veja (Jodelet, 2001; 2005). Assim, a Veja é um meio de comunicação de massa responsável pela construção e disseminação de RS do sindicalismo no contexto brasileiro.

Neste estudo, explorou-se o processo de ancoragem que tem como função dar sentido a um objeto dentro de um contexto (Trindade, Santos \& Almeida, 2014), no caso específico desta pesquisa o objeto é o sindicalismo e o contexto é o da ditadura militar brasileira. Diante da análise dos resultados e da constatação dos diferentes posicionamentos da Veja durante o mapeamento dos sentidos do sindicalismo, destaca-se a importância do contexto histórico, econômico e social para a compreensão do processo de ancoragem do sindicalismo. Com isso, propõe-se discutir o processo de ancoragem dos sentidos do sindicalismo com base em três aspectos históricos centrais na forma de pensar o sindicalismo durante a ditadura militar: (1) a repressão do governo ditatorial aos movimentos sociais; (2) o milagre econômico (1968 a 1974) e a crise econômica (1979 a 1983); (3) o movimento Diretas Já (1983 a 1984).

A análise dos dados demonstrou a intervenção e repressão aos sindicatos e/ ou sindicalistas (C.8) durante a ditadura militar. Foram constatados diversos relatos de utilização da força e violência contra sindicatos e/ ou sindicalistas, inclusive o desaparecimento, tortura, sequestro, morte e assassinato de indivíduos ligados ao sindicalismo. Verificou-se também o desejo do governo ditatorial em interferir na atividade sindical, como, por exemplo, impor tarefas de caráter assistencial aos sindicatos.

De fato, o período da ditadura militar foi caracterizado "pela truculência, repressão e intervenção nas organizações dos trabalhadores" (Queiroz, 2007, p. 25). Nesse período, os dirigentes sindicais foram fortemente perseguidos, a organização de greves foi proibida, os direitos obtidos por meio da CLT foram desmantelados e houve forte intervenção do Estado nos sindicatos (Queiroz, 2007).

Ressalta-se que na pesquisa mais ampla que investigou os quatro períodos históricos foram identificadas 46 categorias de análise. Do conjunto dessas categorias, algumas foram reincidentes em mais de um período histórico e outras apareceram apenas uma vez em períodos históricos específicos. No que tange ao período da ditadura militar, observa-se que a intervenção e repressão aos sindicatos e/ou sindicalistas aparece apenas neste período histórico.

Ademais, durante o período da ditadura militar, os sindicatos e líderes sindicais foram tratados, em alguns casos, como responsáveis pela perturbação da ordem pública (C.7). A atuação sindical foi relacionada às atividades subversivas, agitação social, desordem, financiamento da esquerda, formação de milícias e ao terrorismo. Por esse motivo, os sindicatos e líderes sindicais foram reprimidos e mitigados, com a utilização de forças armadas e até mesmo com a utilização de alguns mecanismos repressores, como bombas de gás lacrimogêneo, sequestro, prisão e tortura (C.8). Vale ressaltar a ancoragem da atuação sindical em categorias pré-existentes e no contexto comum (Trindade, Santos \& Almeida, 2014; Moscovici, 2015), especificamente ao terrorismo e as milícias. Dessa forma, a partir da necessidade de tornar familiar (Moscovici, 2015) as ações radicais 
e extremas do sindicalismo no contexto da ditadura militar, a Veja atribuiu, em alguns momentos, um sentido criminoso, extremista e violento à atuação do sindicalismo brasileiro, ancorando-o no terrorismo e nas milícias.

Em contrapartida, também foi constatado o desejo do regime ditatorial em fortalecer os sindicatos (C.1). Entretanto, pode-se compreender, sugestivamente, que para além desse discurso de fortalecimento, há a intenção do governo de ter o apoio político dos sindicalistas e de intervir e atribuir funções assistenciais e culturais aos sindicatos.

Os dados também demonstraram diversos aspectos negativos da atuação sindical. Foram encontrados alguns casos de sindicalistas considerados pelegos, em que houve o diálogo com o governo, assim como o corporativismo sindical, em que a luta sindical foi direcionada para a conquista de interesses da cúpula e por anseios pessoais sem se consultar a base (C.5). O imposto sindical foi citado como instrumento de corrupção (C.5). Os sentidos observados a partir dos aspectos negativos da atuação sindical estão ancorados (Trindade, Santos \& Almeida, 2014; Moscovici, 2015) na perspectiva de que os sindicatos são organizações que podem contribuir com o processo de melhoria das relações de trabalho e da democratização do país, contudo não estão desempenhando adequadamente esse papel. Esta perspectiva está embasada em sentimentos de frustração, desapontamento e insatisfação.

Alguns líderes sindicais e sindicatos foram tratados como articuladores das mobilizações grevistas contra o governo ditatorial (C.3). No entanto, inicialmente os movimentos grevistas foram fortemente coibidos pela ditadura militar e os relatos sobre a greve concentraram-se nos casos de sindicalistas que clamavam pela greve de forma legal ou ilegal. Com efeito, a greve era considerada ilegal neste período, como determinava a Lei Antigreve (Antunes, 2003). Com a nova conjuntura política e econômica do final da década de 1970, como, por exemplo, o movimento de reabertura política no governo de João Figueiredo em 1979 (Queiroz, 2007), o declínio do crescimento econômico e o aumento da inflação, foram observadas diversas notícias sobre os movimentos grevistas, principalmente as ocorridas na região do ABC Paulista (Singer, 2014).

O ano de 1978 foi importante por marcar o retorno do movimento sindical que não era visto desde $\mathrm{o}$ fracasso do movimento operário de 1968 (Alves, 2000). Esse período de quase 10 anos, chamado por Antunes (2003) como a "noite do sindicalismo brasileiro", foi um longo período de desmobilização do movimento operário e de desgaste do sindicalismo. Com isso, durante o período da ditadura militar foram encontrados excertos que trataram das dificuldades enfrentadas pelo sindicalismo durante o seu ressurgimento, como a desunião dos trabalhadores, a debilidade dos sindicatos, o reduzido número de trabalhadores sindicalizados e a inexperiência dos novos líderes sindicais (C.6).

Os dados também demonstraram o surgimento de algumas figuras combativas e influentes que identificaram o novo sindicalismo brasileiro a partir de 1978. Assim, constatou-se uma ênfase ao líder sindical Luiz Inácio da Silva, o Lula, como principal articulador dos movimentos grevistas e também como responsável pela renovação sindical brasileira (C.9). Como afirma Antunes (2003), foi nesse período que Lula se consolidou como liderança sindical, com o apoio de todos os sindicatos do país que lutavam contra o regime opressor. A análise dos dados indicou ainda que Lula recebeu um tratamento análogo ao recebido por celebridades nas páginas da Veja, com direito a matérias que tratavam de sua vida pessoal e profissional e as suas glórias diante do movimento sindical.

Também se detectou que a figura de Lula e o sindicalismo brasileiro foram associados ao surgimento do PT e da CUT. Os dados indicaram que o PT e a CUT foram identificados como a materialização do novo posicionamento político e ideológico dos sindicatos brasileiros. Nesse sentido, o PT, a CUT e principalmente o Lula objetivam o sindicalismo durante o período da ditadura militar, pelo fato de darem concretude e materialidade (Moscovici, 2015) ao fenômeno sindicalismo. Isto é, o sindicalismo brasileiro foi fortemente relacionado à imagem de Lula, do PT e da CUT nas páginas da Veja durante a ditadura militar. Nesse contexto, emergiu no Brasil a atuação político-partidária do sindicalismo. O PT e a CUT tornaram-se uma força política e social que influenciou o movimento Diretas Já e o processo de redemocratização (Boito Jr., 2005).

De fato, com a formação do novo sindicalismo, os sindicatos demonstraram todo o seu poder e influência por meio das conquistas obtidas pelos movimentos grevistas (C.3) que, de certa forma, geraram preocupação ao governo ditatorial. Aliás, esse período foi marcado 
pela estagnação da economia e pela aceleração dos índices inflacionários (Marques \& Rêgo, 2010). A crise do petróleo de 1979 em meio à crise do endividamento externo do Brasil provocou o descontrole dos preços e o desemprego em massa (Singer, 2014). Nesse contexto, o movimento sindical brasileiro teve apoio de diversos movimentos populares e democráticos durante a greve de 1979 (Boito Jr., 2005). O movimento sindical brasileiro foi incluído no conjunto de movimentos de esquerda, como parte da imprensa brasileira e os movimentos pela anistia e contra a carestia (Boito Jr., 2005). Assim, alguns excertos demonstraram que o novo sindicalismo, mesmo que ainda duramente reprimido pelo regime militar (Cardoso, 2002), foi tratado como importante para o país (C.1), por exemplo, nos trechos em que o sindicalismo foi apresentado como um fator de iluminação e progresso da sociedade e como importante para a eficiência da economia do país. Além disso, a análise dos dados indicou a importância dos sindicatos nas negociações e intermediação de conflitos de interesse entre a classe trabalhadora e o governo e/ ou patronato (C.2). Com isso, os dados demonstraram a importância de se ter sindicatos fortes para a defesa dos direitos dos trabalhadores (C.1).

No momento posterior, estruturou-se o movimento Diretas Já, que teve como objetivo reivindicar as eleições presidenciais diretas. A campanha das Diretas Já contou com a intensa mobilização e participação da classe dos trabalhadores, sindicatos e da sociedade civil em geral (Alves, 2000). Nesse cenário, verificase que os sentidos veiculados pela Veja direcionam a formação de uma RS do sindicalismo que também o apresenta como fundamental aos trabalhadores e à sociedade. A disseminação dos sentidos de liberdade e vigor do novo sindicalismo refletem o desejo de reabertura política e, consequentemente, do fim da repressão aplicada pela ditadura militar. Esse anseio pelo retorno da democracia era apoiado principalmente por estudantes, igrejas, sindicatos de trabalhadores e demais setores da sociedade que se dispuseram a manifestar contra o governo ditatorial (Boito Jr., 2005). Dessa forma, observa-se que as RS do sindicalismo na Veja também estão ancoradas (Trindade, Santos \& Almeida, 2014; Moscovici, 2015) em valores, tais como RS de liberdade, autonomia e democracia. Além disso, verifica-se também a ancoragem das RS de sindicalismo na possibilidade de transformação da sociedade por meio da mobilização, da autenticidade, da inovação e da negociação.

No conjunto, os dados indicaram diversos nuances dos valores, normas e sentidos do sindicalismo, por exemplo, os sentidos de renovação e vigor do sindicalismo (C.3) e, em contrapartida, o envolvimento dos sindicalistas com atos de corrupção (C.5) e as dificuldades enfrentadas pelos sindicatos (C.6). O discurso polarizado entre defesa (C.4) e crítica (C.7) também demonstra a contraditoriedade dos sentidos do sindicalismo na Veja. Em alguns casos, os dados demonstraram crítica da Veja ao governo ditatorial, como nos excertos que demonstraram desejo e apoio pela abertura política, insinuaram a importância da luta sindical para a abertura política, apoiaram a liberdade sindical e apresentaram críticas à repressão sofrida pelos sindicatos. Todavia, o sindicalismo também foi criticado pela Veja devido a alguns prejuízos que as greves ocasionaram à indústria e à economia, assim como foi demonstrada certa preocupação com as badernas e depredações ocasionadas pelos movimentos grevistas e com o anseio demasiado dos trabalhadores por aumentos salariais. Portanto, as categorias C.4 e C.7 também exemplificam a contraditoriedade e a dinamicidade das RS, em que ora a Veja defende as ações dos sindicatos e líderes sindicais perante o regime opressor, ora os critica por perturbarem a ordem pública e os considera como um empecilho para o desenvolvimento econômico. Esta dinâmica elucida a afirmação de Sá (1998) de que as RS estão em constante movimento e são multifacetadas, difusas e até mesmo contraditórias.

Esses diferentes cenários apresentam o contexto de uma época em que estão inseridos valores e afetos no qual estão ancoradas as RS do sindicalismo. A ditadura militar é um momento da sociedade brasileira em que os valores tais como liberdade e democracia foram negados e ameaçados, mas ao mesmo tempo conviveuse com os valores de oposição e enfrentamento ao regime ditatorial. Os dados demonstram justamente essa duplicidade na construção dos sentidos do sindicalismo. Verifica-se dessa forma que os sentidos veiculados pela Veja, que favorecem a formação das RS de sindicalismo, estão ancorados (Moscovici, 2015) nesses diferentes valores.

O contexto econômico e as consequentes transformações das relações de trabalho foram essenciais para a compreensão dos sentidos atribuídos pela Veja ao sindicalismo brasileiro. A análise das transformações do mundo do trabalho (C.10) indica que as relações de trabalho foram consideradas como um fator essencial para o ressurgimento da luta sindical e para o fortalecimento do sindicalismo 
e, em contrapartida, ocasionou os conflitos entre governo e sindicatos, assim como os sindicatos foram responsabilizados pelas novas exigências trabalhistas.

Por fim, a discussão do processo de ancoragem dos sentidos do sindicalismo a partir da repressão do governo ditatorial aos movimentos sociais, do milagre econômico, da crise econômica e do movimento Diretas Já apresenta o contexto político, social e econômico em que estão inseridos afetos e valores nos quais estão ancoradas as RS do sindicalismo. Desse modo, os sentidos do sindicalismo estão adstritos a sensações e a valores. Assim, durante a ditadura militar, os diversos sentidos veiculados pela Veja sobre o sindicalismo estão ancorados em diversos valores, sensações e significados, quais sejam, ressurgimento, inovação, liberdade, autenticidade, autonomia, poder, êxito, mobilização, negociação, assistencialismo, peleguismo, corrupção, fracasso, inexperiência, radicalismo, baderna e subversão. Esses valores, sensações e significados são organizadores da realidade social (Jodelet, 2001; 2005) e contribuem para a construção dos sentidos do sindicalismo na sociedade brasileira. Além disso, a ancoragem dos sentidos do sindicalismo demonstra a complexidade de valores e significados que são atribuídos ao fenômeno sindicalismo pelos meios de comunicação de massa. Semelhantemente à pesquisa inaugural de Moscovici (2012), constata-se que o sindicalismo deixa de ser apenas um movimento social da classe trabalhadora e recebe uma conotação complexa no campo do senso comum.

A diversidade de sentidos e a contraditoriedade das RS do sindicalismo demonstram parte das representações partilhadas (Jodelet, 2001) sobre o sindicalismo que circularam e ainda circulam na sociedade brasileira, uma vez que os conteúdos são retomados e renovados a cada novo encontro do indivíduo com o objeto em um determinado contexto social (Jodelet, 2005). Ademais, a diversidade, contraditoriedade e dinamicidade também demonstram a complexidade das RS do sindicalismo. Todavia, os elementos contraditórios são organizados de maneira que a realidade social faça sentido (Jodelet, 2001), ou seja, ressalta-se que o ambiente social dinâmico e complexo concebe RS diversificadas e coerentes (Jodelet, 2001).

\section{Considerações finais}

Os resultados apresentados neste artigo fazem parte de um projeto de pesquisa mais amplo (Peroni, 2015) que investigou os sentidos do sindicalismo disseminados na Veja em quatro períodos da história brasileira. O foco de atenção do texto recai sobre a ditadura militar, período marcado pela truculência, perseguição e repressão ao sindicalismo (Queiroz, 2007). Dessa forma, o objetivo deste artigo foi identificar e analisar os sentidos do sindicalismo disseminados pela Veja durante o período da ditadura militar (1968-1985).

Para viabilizar teoricamente o estudo recorreuse à TRS para analisar o objeto representacional sindicalismo no contexto histórico da ditadura militar, sob a perspectiva do processo de ancoragem (Trindade, Santos \& Almeida, 2014, Moscovici, 2015), para identificar os diversos sentidos disseminados pela Veja, por meio de uma pesquisa documental de natureza qualitativa. As RS são uma forma de conhecimento social que cooperam para a construção de uma realidade comum (Jodelet, 2001). A análise dos dados indicou que a repressão do governo ditatorial aos movimentos sociais, o milagre econômico, a crise econômica e o movimento Diretas Já são aspectos históricos centrais para a compreensão do sindicalismo, assim como ancoram os sentidos do sindicalismo durante o período da ditadura militar.

Os resultados da pesquisa indicaram uma pluralidade de sentidos sobre o sindicalismo disseminados socialmente. As relações de trabalho e o contexto de crise econômica foram considerados como fatores importantes para o ressurgimento da luta sindical e para o fortalecimento do sindicalismo, e, em contrapartida, ocasionaram os conflitos entre governo e sindicatos. O novo sindicalismo surgiu com uma postura radical e esquerdista e foi fortemente combatido e reprimido pelo governo ditatorial, no entanto, foi inserido positivamente no pensamento social num conjunto de entidades e sujeitos importantes para a reabertura política e implantação e desenvolvimento da democracia.

O processo de ancoragem demonstrou os diversos valores, sensações e significados em que os sentidos do sindicalismo estão ancorados (Moscovici, 2012). Ademais, os valores, sensações e significados atribuídos ao sindicalismo são organizadores da realidade social e, dessa forma, constroem os sentidos do sindicalismo na sociedade brasileira (Jodelet, 2001). Diante disso, tem-se que a presente pesquisa contribui para o campo dos Estudos Organizacionais e para o aprofundamento das discussões sobre o sindicalismo. Assim, este estudo demonstra a viabilidade de pesquisas que evidenciem a construção e a atribuição 
de sentidos aos fenômenos intrínsecos aos Estudos Organizacionais no universo do senso comum, uma vez que as RS de um objeto social são organizadoras da realidade e, dessa forma, influenciam e constroem o contexto econômico, político, social e organizacional.

A análise dos dados também proporcionou aprofundamento na história do sindicalismo e suas significações e sentidos. Sob a ótica da Veja, constatouse empiricamente a participação e a influência mútua do movimento sindical na política e nos rumos econômicos do Brasil. A quantidade e relevância dos dados levantados neste trabalho demonstram a grande repercussão do sindicalismo na Veja, o que torna incontestável o importante lugar que o sindicalismo tem ocupado no debate político e social brasileiro.

O estudo tem como limitação a não priorização das características morfológicas das matérias jornalísticas. Além disso, a pesquisa não analisou os efeitos dos textos jornalísticos no público alvo e não investigou os sentidos do sindicalismo após o período da ditadura militar. Todavia, esses delineamentos não interferiram na análise e tornam-se sugestões de pesquisa para estudos futuros.

Enfim, Clémence, Green e Couvoisier (2014) destacam a intenção dos meios de comunicação de massa em atrair a atenção do público com mensagens que os façam comprar um jornal ou revista. Assim, as informações são tratadas pelos meios de comunicação de massa de acordo com o que interessa ao público alvo e numa linguagem adequada ao senso comum. Os meios de comunicação de massa juntamente com outros processos sociais tais como as conversações, têm um papel importante na construção das RS na medida em que fornecem elementos para transformar em familiar aquilo que não é familiar por meio do processo de ancoragem (Trindade, Santos \& Almeida, 2014; Moscovici, 2015).

Desta forma, por meio do processo de ancoragem foi possível analisar a tradução do sindicalismo no senso comum (Clémence, Green \& Couvoisier, 2014; Moscovici, 2015). Isto é, foi possível acompanhar a dinâmica dos sentidos do sindicalismo ao sair de seu plano conceitual e passar por transformações de acordo com o perfil do público alvo, o contexto histórico, político e econômico do país e as afiliações política e ideológicas da linha editorial da Veja. Com isso, ressalta-se que a análise dos fatos noticiados pela Veja não generaliza ou dimensiona as RS sobre o sindicalismo que circulam na mídia e na sociedade brasileira, porém, permitiu compreender alguns dos elementos que permeiam e constroem os sentidos do sindicalismo.

\section{Referências}

Almeida, A. M. O. (2009). Abordagem societal das representações sociais. Sociedade e Estado, 24(3), 713737. Recuperado em 31 de agosto, 2018, de http:/ / www.redalyc.org/html/3399/339930897002/

Alves, G. (2000). Do "novo sindicalismo" a "concertação social": Ascensão (e crise) do sindicalismo no Brasil (1978-1998). Revista Sociologia Política, (15), 111-124. Recuperado em 23 de novembro, 2017, de https:/ / repositorio. unesp.br/bitstream/handle/11449/10829/S010444782000000200008.pdf? sequence $=1$ \&is Allowed $=y$

Antunes, R. L. C. (2003). O Que é Sindicalismo. São Paulo: Brasiliense.

Antunes, R. L. C. (1996). Mundo do Trabalho e Sindicatos na Era da Reestruturação Produtiva: Impasses e Desafios do Novo Sindicalismo Brasileiro. Transinformação, 8(3), 130-137. Recuperado em 31 de agosto, 2018, de http://periodicos.puccampinas.edu.br/seer/index.php/transinfo/article/ view/1606/1578

ANER - Associação Nacional de Editores de Revistas. (2015). Circulação: Revistas semanais - 2013 X 2014 (jan. a set.). Recuperado em 31 de agosto, 2018 de http://aner.org.br/dados-de-mercado/circulacao/

Augusti, A. R. (2008). Os principais valores presentes no discurso jornalístico da revista Veja. Rumores, 1(2), 1-14. doi: http://dx.doi.org/10.11606/issn.1982-

677X.rum.2008.51112

Bardin, L. (2011), Analise de conteúdo. Lisboa: Edições 70.

Bauer, M., Gaskell, G., \& Allum, N. (2002), Qualidade, quantidade e interesses do conhecimento: Evitando confusões. In M. Bauer \& G. Gaskell (Orgs.). Pesquisa qualitativa com texto, imagem e som (pp. 17-36). Rio de Janeiro: Vozes.

Boito, A. Jr. (2005). A presença do sindicalismo na história política do Brasil. In A. Jr. Boito (Org.). O sindicalismo na politica brasileira (pp. 265-291). Campinas, SP: UNICAMP, Instituto de Filosofia e Ciências Humanas. 
Brandão, L., \& da Silva, M. H. (2017). A emergência do neoliberalismo no Brasil: um estudo sobre a revista Veja no contexto das eleições presidenciais de 1989. Estudos em Comunicação, (24), 27-42. doi: 10.20287/ec.n24.a02

Brym, R., Roberts, L., Lie, J., \& Rytina, S. (2012). Sociology: Your compass for a new world. ( $4^{\text {a }}$ ed.). Toronto: Nelson.

Cardoso, A. M. O. (2002). Sindicalismo no Brasil: Breve excurso sobre mudanças e permanências. In A. M. O. Cardoso (Org.). Sindicalismo e relações trabalhistas (pp. 11-34). Rio de Janeiro: Fundação Konrad Adenauer.

Castro, C. A.P. (2007). Sociologia aplicada à administração. ( $2^{\mathrm{a}}$ ed.). São Paulo: Atlas.

Clémence, A., Green, E., \& Courvoisier, N. (2014), Comunicação e ancoragem: A difusão e a transformação das representações. In A. M. O. Almeida, M. F. S. Santos \& Z. A. Trindade (Orgs.). Teoria das representaçoes sociais: 50 Anos (pp. 237-257). Brasília: Technopolitik.

Colbari, A. (2014). A análise de conteúdo e a pesquisa empírica qualitativa. In E. M. Souza (Org.). Metodologias e analiticas qualitativas em pesquisa organizacional: Uma abordagem teórico-conceitual (pp. 241272). Vitória: EDUFES.

Cotanda, F. C. (2008). Os sindicatos brasileiros em face das inovações tecnológicas e organizacionais. Dados - Revista de Ciências Sociais, 51(3), 617-646. Recuperado em 31 de agosto, 2018 de https://www. lume.ufrgs.br/handle/10183/149032

Franco, M. L. P. B. (2003). Análise de Conteúdo. Brasília: Editora Plano.

Grupo Abril. (2015). Quem somos: história. Recuperado em 31 de agosto, 2018 de http://grupoabril.com.br/ pt/quemsomos/ historia

Guareschi, P. A. (2003). Construtores da informação: Meios de comunicação, ideologia e ética. (2a ed.). Petrópolis, RJ: Vozes.

Herz, D. (2003). Prefácio. In P. A. Guareschi. Construtores da informação: Meios de comunicação, ideologia e ética. (2a ed., pp. 11-25). Petrópolis, RJ: Vozes.
Jodelet, D. (2005). Experiência e representações sociais. In S. S. Menin \& A. M. Shimizu (orgs). Experiência e representação social: questões teóricas e metodológicas (pp. 23-56). São Paulo: Casa do Psicólogo.

Jodelet, D. (2001). Representações sociais: Um domínio em expansão. In D. Jodelet (Org.). As representaçoes sociais (pp. 17-44). Rio de Janeiro: EdUERJ.

Klanovicz, L. R. F. (2010). No olho do furacão: Revista Veja, censura e ditadura militar (1968-1985). Literatura em Debate, 4(6), 34-50. Recuperado em 31 de agosto, 2018 de http:/ /www.revistas.fw.uri.br/ index.php/literaturaemdebate/article/view/535

Marques, R. M., \& Rêgo, J. M. (2010), Economia Brasileira. ( $4^{a}$ ed.). São Paulo: Saraiva.

Menandro, M. C. S., Trindade, Z. A., \& Almeida, A. M. O. (2003). Representações sociais da adolescência/juventude a partir de textos jornalísticos (1968-1974 e 1996-2002). Arquivos Brasileiros de Psicologia, 55(1), 42-55. Recuperado em 31 de agosto, 2018, de http:/ / pepsic.bvsalud.org/ pdf/arbp/v55n1/v55n1a06.pdf

Mira, M. C. (2001). O leitor e a banca de revistas: a segmentação da cultura no século XX. São Paulo: Olho dÁgua/Fapesp.

Mira, M. C. (1997). O leitor e a banca de revistas: O caso da editora Abril. Tese de Doutorado em Sociologia, Instituto de Filosofia e Ciências Humanas da Universidade Estadual de Campinas, Campinas.

Moscovici, S. (2012). A psicanálise, sua imagem e seu público. Petrópolis: Vozes.

Moscovici, S. (2015). Representações sociais: Investigações em psicologia social (11ª ed.). Petrópolis, RJ: Vozes.

Peroni, G. G. H. (2015). Os sentidos do sindicalismo na revista Veja: Um estudo em representações sociais. Dissertação de Mestrado em Administração, Universidade Federal do Espírito Santo, Vitória, ES, Brasil.

Queiroz, A. A. (2007). Movimento sindical: Passado, presente e futuro. In J. R. Inácio (Org.). Sindicalismo no Brasil: Os primeiros 100 anos? (pp. 19-44). Belo Horizonte: Crisálida. 
Rautenberg, E. (2012). A construtora Mendes Júnior na revista Veja: Imprensa, empreiteiras e ditadura civil-militar brasileira. Espaço Plural, 13(27), 158-177. Recuperado em 10 de setembro, 2018, de http:// www.redalyc.org/pdf/4459/445944369012.pdf

Rosa, M. (2004). As novas faces do sindicalismo rural brasileiro: A reforma agrária e as tradições sindicais na Zona da Mata de Pernambuco. Dados - Revista de Ciências Sociais, 47(3), 473-503. Recuperado em 31 de agosto, 2018, de http://www.scielo.br/pdf/\%0D/ dados/v47n3/a02v47n3.pdf

Sá, C. P. (1998). A construção do objeto de pesquisa em representações sociais. Rio de Janeiro: EdUERJ.

Sá-Silva, J., Almeida, C. D., \& Guidani, J. F. (2009). Pesquisa documental: Pistas teóricas e metodológicas. Rev. Bras. de História \& Ciências Sociais, 1(1), 1-15. Recuperado em 23 de novembro, 2017, de https:// www.rbhcs.com/rbhcs/article/view/6/pdf

Santana, M. A. (2002), O sindicalismo brasileiro nos anos 1980/2000: Do ressurgimento à reorientação. In A. M. Cardoso (Org.), Sindicalismo e relações trabalhistas (pp. 35-49). Rio de Janeiro: Fundação Konrad Adenauer.

Schroder, C. Apresentação. (2003). In P. A. Guareschi. Construtores da informação: Meios de comunicação, ideologia e ética. (2 a ed., pp. 11-25). Petrópolis, RJ: Vozes.

Singer, P. (2014). O processo econômico. In D. A. Reis (Org.). Modernização, ditadura e democracia 19642010 (Vol. 5, pp. 183-231). Rio de Janeiro: Objetiva.

Thompson, J. B. (2002). Ideologia e cultura moderna: Teoria social crítica na era dos meios de comunicação de massa. ( $6^{\mathrm{a}}$ ed.). Petrópolis, RJ: Vozes.

Trindade, Z. A., Santos, M. F. S., \& Almeida, A. M. O. (2014). Ancoragem: Notas sobre consensos e dissensos. In Z. A. Trindade, M. F. S. Santos \& A. M. O. Almeida (Orgs.). Teoria das representações sociais: 50 anos (pp. 133-162). Brasília: Technopolitik. 